\title{
PRIORITISATION OF TRAFFIC COUNT LOCATIONS FOR TRIP MATRIX ESTIMATION USING INFORMATION THEORY
}

\author{
Manju V. Saraswathy ${ }^{1}$, Kuncheria P. Isaac ${ }^{2}$ \\ ${ }^{1}$ Department of Civil Engineering, College of Engineering Trivandrum, India \\ ${ }^{2}$ All India Council for Technical Education, India
}

Received 27 December 2012; accepted 29 March 2013

\begin{abstract}
The foremost step in estimation of OD matrix from link volume counts is the systematic selection of optimum links. This paper suggests a methodology to prioritise the links in a road network using information theory. Weights are assigned to the links based on its information content and the optimum links which satisfies the OD covering rule is selected by Binary Integer Programming (BIP). The selected links are prioritised based on the assigned weights. The methodology is applied on a hypothetical network. The procedure is validated by calculating the error of the OD matrix estimated with the traffic volumes on the selected links as input. It is observed that the OD matrix estimated with links selected by information theory based approach provided the least error. It was also found that the method of prioritisation discussed here is suitable when there are budgetary constraints for selection of input links.
\end{abstract}

Keywords: OD matrix, information theory, traffic count location, link volume.

\section{Introduction}

The transportation planning process involves the knowledge of the transport demand between various zones in the city/area proposed for development. The demand between the various zones is represented in the form of a matrix called the Origin Destination (OD) matrix. There are three methods for estimating the OD matrix namely, direct sample estimation, model estimation and indirect estimation from traffic flows. In direct sample estimation, the traditional methods such as home interview method and the road side interview method are adopted. In model estimation method, the OD matrix is estimated by applying a system of models that give the number of journeys made by a certain mode during a certain period of time, the parameters being estimated on the basis of primary surveys. These methods are costly and time consuming. Thus, there arises a need for the indirect determination of OD matrix using comparatively inexpensive data like the traffic counts.

\section{Relevant Literature}

Starting from Vanzuylen and Willumsen (1980), quite a number of studies have been conducted in the area of OD matrix estimation which include Hazelton (2000), Hazelton (2003), Sherali et al. (2003), Baek et al. (2004), Wong et al. (2005), Doblas and Benitez (2005), Ehlert et al. (2006) and Yang et al. (2006). The first attempt towards modelling OD matrix estimation as a multi objective optimisation problem was done

${ }^{1}$ Corresponding author: manjuvs@cet.ac.in 
by Gothe et al. (1989). Nagaraj and Samson (1992) adopted the same modelling approach and they employed the Goal Programming technique to solve the optimisation problem by updating the seed matrix.

Studies have revealed that the quality of the OD estimate is highly dependent on the number and location of traffic counts; the higher the number, the accuracy will be more. Due to time and money constraints, often it becomes difficult to have a large number of traffic count locations, but at the same time, efficiency of estimation cannot be compromised. Hence, it is necessary to look for some criteria to select an optimum number of traffic counting locations. Different sets of traffic counts may give different results and the quality of estimated trip matrix is dependent on the quality of input traffic data, and hence the selection of links for traffic counts is significant.

Yang et al. (1991) studied the reliability of OD matrix estimate by taking into account the number of traffic counts and their locations. It was observed that different sets of traffic counts did not contain the same amount of information. A solution was arrived at by Nagaraj and Samson (1992) when they evolved a procedure for selection of links by grouping the links carrying trips from identical zonal pairs. This was done by introducing two indices namely $\mathrm{K}$ index and $\mathrm{L}$ index, which reflected the considerations for the choice of links. Yang and Zhou (1998) stated four basic rules of locating traffic count points: OD covering rule, maximal flow fraction rule, flow intercepting rule and link independence rule. The problem was formulated such that the OD covering rule and link independence rule were incorporated as constraints and the total net traffic flows observed were taken as the objective function to be maximised. Kim et al. (2003) formulated the link selection problem as the one which minimises the total cost of traffic counting and at the same time cover all OD pairs. They developed two models: the link based model which minimises the cost for obtaining link traffic counts and road based model which minimises the total cost of traffic counting for the selected link and its reverse link. Yang et al. (2003) formulated the traffic count location problem as an integer mathematical program which was solved using GA based sequential greedy algorithm. A numerical problem was used to illustrate the procedure. The rules stated by Yang and Zhou (1998) were considered for developing the methodology. Gan et al. (2005) made a joint investigation of the traffic counting location, estimation method and error bound in an integrated manner. They found that, once sufficient counting links are located to separate all OD pairs, the resulting OD estimates are not vulnerable to the route choice models and congestion levels. Ehlert et al. (2006) debated about various Binary Integer Programming (BIP) formulations for minimising count locations which satisfied the rules stated by Yang and Zhou (1998). The software 'OptTool' developed by Ehlert et al. (2006) incorporated the option to provide weights to the OD pairs on the basis of the information content of the OD movements. Cipriani et al. (2006) developed two models, one based on heuristic rules and other based on genetic algorithm which maximised the OD pair's coverage. Yang et al. (2006) resorted to the column generation procedure and the branch and bound technique to find the optimal counting locations that satisfied the $\mathrm{OD}$ covering rule. Wang et al. (2008) developed a micro simulation model to solve the network count location problem. Lorenzo et al. (2010) adopted different sampling procedures for selection of links and found that the quality of OD matrix estimated varies with different sets of links. It has been widely agreed by the researchers that the link flows should cover 
all OD pairs, but in large networks, where the number of OD pairs is too large, this may be impractical. Bera and Rao (2011) provided an extensive review of literature related to $\mathrm{OD}$ matrix estimation. They discussed the static and dynamic estimation of OD matrix and touched upon the rules related to the selection of optimum counting locations. Boschetti et al. (2011) modelled the OD matrix estimation problem as a constrained quadratic estimation problem. Assuming that a counter will provide traffic flows in both directions, they provided a Lagrangean approach to solve the network count location problem.

\section{Need for the Study}

Review of works reported under OD matrix estimation has revealed that the accuracy of the estimated OD matrix is affected by the selection of input links. Hence ordering of links is necessary. However, the ordering of links depending on its importance was overlooked in most of the studies. Different sets of input link counts are known to produce different trip matrices. The selection of input links changes the quality of the estimated matrix as seen in Lorenzo et al. (2010). However, very few works have considered this aspect. Most of the researchers are of the opinion that the link flows should satisfy the OD covering rule, which states that the counting points on a road network should be so located that a certain portion of trips between any OD pair will be observed. When there are budgetary constraints, counts cannot be carried out on all the links to satisfy the OD covering rule. Then, the optimum number of links which satisfies the OD covering rule should be ranked in the order of their importance and the links for conducting traffic counts for OD matrix estimation can be selected from the prioritised set according to available funds. The previous studies except that of Ehlert et al. (2006) gave either equal weights for all links or the cost of installing traffic detector in a link was taken as its weight. In this paper, a methodology is suggested to prioritise the links in a road network on the basis of its information content based on the information theory developed by Shannon (1948). Information theory is a branch of applied mathematics and electrical engineering involving the quantification of information. Historically, information theory was developed by Shannon (1948), to find the fundamental limits on compressing, reliably storing and communicating data. Information theory, since its inception, has been widely used to calculate the information content in a communication network and has found applications in many other areas, generally networks. The transportation network can be considered to be similar to the communication network and so this theory could be considered to be valid for the road network also.

\section{Methodology}

The present study makes use of information theory for ranking the links in a network. The weights of the OD pairs are found out by applying information theory and the weights of the links are determined based on the weights of the OD pair using the links. The optimum links which satisfy the OD covering rule are identified. To simplify the OD matrix estimation problem, the multi objective formulation which minimises the deviation between the observed and estimated traffic counts while satisfying the trip production and attraction constraints is adopted. Genetic algorithms are better than conventional algorithms as an optimisation tool as they are more robust (Goldberg, 2004). Genetic algorithm has the advantage that it starts from a number of solutions and for this reason genetic algorithm is used as an optimisation tool in this study. In order 
to preserve the structure of the prior matrix, additional information in the form of upper and lower bounds for trip values are provided.

\subsection{Ranking of Links by Assigning Weights}

For indirect estimation of OD matrix, it is obligatory to provide the link volume counts as input. A network may comprise of a number of links and collecting all link volumes for input involves a lot of time besides being expensive. The cost of conducting traffic counts can be minimised by keeping down the number of traffic counting locations. Random selection of links will not produce optimum results. Since different sets of input links give different results, it is imperative to prioritise the links in the network and select the input links from the prioritised set as per budget availability. In view of this, a procedure is required to select the optimum links for traffic volume collection and to prioritise these links. As per the budget constraints, the links can be chosen from the prioritised set for OD matrix estimation.

From the review of literature, it is seen that the cost of counting of traffic volume in links is the major criterion for selection of links. The cost of counting on a link is taken as the cost of installation of detectors. If the number of input links for OD matrix estimation is minimised, the cost is also minimised. It has been established in the literature that to estimate a reliable OD matrix, the input links should satisfy the OD covering rule. This is expressed as a minimisation problem which takes the following form (Kim et al., 2003):

Minimise

$Z=\sum_{a=1}^{L} C_{a} l_{a}$
Subject to

$\sum_{a=1}^{L} \delta_{a w} l_{\mathrm{a}} \geq 1$ for all OD pairs $w \in G$

where,

$Z$ - Objective Function

$G$ - Set of all OD pairs

$C$ - Cost of traffic counting for link $a$

$L$ - Total links in the network

$l_{a}=1$, if link $a$ is selected, 0 otherwise

$\delta_{a w}=1$, if OD pair $w$ is covered by the link $a$, 0 otherwise.

The solution of this minimisation problem results in the selection of links with minimum cost of counting while ensuring that all OD pairs are covered.

In the present study, instead of the cost, some weights are attached to the links and this enables to select the links based on their importance. Since the link selection is a minimisation problem, lower the coefficient of $l_{a}$ in Eq. (1), the higher the chance of link a being selected. Hence, $C_{a}$ is replaced by the inverse of weight of links in Eq. (1). This ensures that the links with maximum weight is given the highest priority and has more probability for being selected. Hence, Eq. (1) is revised in this study as follows.

Minimise $\mathrm{Z}=\sum_{a=1}^{L}\left(\frac{1}{W_{a}} l_{a}\right)$

Subject to Eq. (2).

where,

$W_{a}$ - Weight of the link $a$. 
Two criteria are adopted for fixing the weights to the links. The first criterion is based on the traffic volume on the links and the second criterion is based on the information content of the links as per information theory.

\subsubsection{Weights Based on Prior Link Flow}

If a prior link flow data is available, it can be utilised to fix the weights for the links. The links with higher volume per interchange can be considered to be more important than other links and hence the volume per interchange of a link is taken as its weight. Therefore,

$$
W_{a}=\frac{V_{a}}{n_{a}}
$$

where,

$V_{a}$ - Traffic volume on link $a$ from prior data $n_{a}-$ Number of OD pairs using link $a$.

\subsubsection{Information Theory Based Weights for Links}

If a prior trip matrix is available, that information can be used to fix the weights of the OD pairs and the links. This approach follows the information theory and is based on the information content in the prior OD flows. Information theory has been found to have application in the field of OD matrix estimation starting from Vanzuylen and Willumsen (1980). As per information theory, the entropy $H$ of a discrete random variable $X$ is a measure of the amount of uncertainty associated with the value of $X$. The information content, i.e. the entropy of a particular symbol $x$ is calculated from the probability of its occurrence $(p(x))$ using the following formula (Eq. (5)).

$$
H(x)=-p(x) \cdot \log p(x)
$$

A transportation network with trip flows can be considered to be similar to a communication network with data flows. If $p\left(t_{i j}\right)$ is the probability that a trip originating from zone $i$ is attracted to zone $j$, as per information theory, the information content of OD pair ij can be given by Eq. (6).

$H_{i j}=-p\left(t_{i j}\right) \cdot \log p\left(t_{i j}\right)$

where,

$P\left(t_{i j}\right)=\frac{t_{i j}}{\sum_{j} t_{i j}}$ for all origins

$\sum_{j} P\left(t_{i j}\right)=1$

$P\left(t_{i j}\right)$ - Probability of occurrence of $t_{i j}$

$t_{i j}$ - Trips between $i$ and $j$ in the prior OD matrix

$i=1,2, \ldots, N$

$j=1,2, \ldots, N$

$N$ - Total number of zones in the network.

The information content $H_{i j}$ can be taken as the weight for the OD pairs. The weight of the links is taken as the cumulative weight of all OD pairs using that link. The weight of a link $a$ is calculated as Eq. (8).

$W_{a}=\sum_{w \in G} \lambda_{w}^{a} H_{w}$

for all OD pairs $w \in G$ using link a

where,

$\lambda_{w}^{a}$ - Proportion of trips between OD pair $w \in G$ using link $a$ 
$H_{w}$ - Weight of OD pair $w \in G$.

In the present study, the prior link flow and prior trip matrix is made use of to determine the weights of the links in the network, and then to select the links which satisfy the OD covering rule using binary integer programming. The selected links are prioritised based on the weights assigned to the links. The links with more weight is given higher priority for selection as traffic count locations as these links are expected to give better results in the trip estimation process.

\subsection{Testing the Methodology}

The procedure developed for link selection, is demonstrated on a hypothetical network. The hypothetical network consists of 8 zones (numbered 1 to 8 ), 10 nodes (numbered 9 to 18 ) and 48 links (24 two way links) and is shown in Fig. 1. Even though both link selection and route selection affects the OD matrix estimation process, this study concentrates only on link selection and the route choice is considered to be fixed for the network. Hence, the network is assumed to be uncongested and that the travellers were using the shortest path. The OD matrix given in Table 1 is the target OD matrix. The values in the table indicate the number of person trips between zones. The traffic volume on all the links were obtained by assigning the target OD matrix on the network given in Table 1 . The target OD matrix is assumed to be unknown (hidden) and the proposed methodology is used to estimate this OD matrix from partial link volume counts.

\subsubsection{Identification of Optimum Links}

The optimisation problem for link selection given in Eq. (3) is in the form of binary integer programming and the solution gives

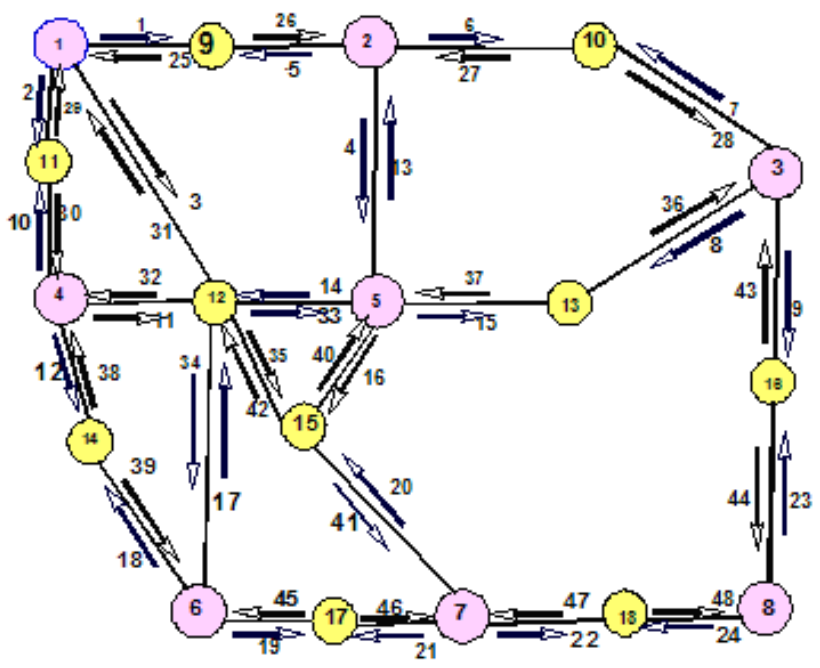

Fig. 1.

Hypothetical Network 
the value for $l_{a}$, as either 0 or 1 . The constraint given in Eq. (2) ensures that the selected links cover all OD pairs. Bintprog function in MATLAB uses a Linear Programming (LP) based branch-and-bound algorithm to solve binary integer programming problems. The objective function in Eq. (3) was solved by Bintprog function. The weights of links $W_{a}$ in the objective function were calculated based on prior link flow (Eq. (4)) and using information theory based approach as in Eq. (8). For information theory based approach, the probabilities were calculated from the target matrix. Thus, the links were selected by link flow method and information theory based method. For comparison, the links were also randomly selected by assigning equal weight to all links (equal weighting method). When links are given equal weights, the first set of links which satisfy the OD covering rule were selected. If the links are rearranged, a new set of links will be selected. The links selected by information theory based weighting, link flow based weighting and by equal weighting approach are given in Table 2.

\subsubsection{Prioritisation of Links}

The selected links are arranged in the order of its weights in Table 2. Among the links selected by information theory based method, it can be seen that link 33 has more weight followed by link 20 and so on and as per link flow method, link 6 has more weight followed by link 48 . The OD pairs covered for the addition of links were found out for all the three cases. Fig. 2 shows the increase in OD pairs covered with addition of links. When links are arranged based on information theory, more number of $O D$ pairs are covered with the same number of input links compared to the other two methods.
When six links were the input, the links selected by information theory based method covered $53 \%$ of the OD pairs, while the links selected by equal weighting method covered $30 \%$ of the OD pairs and that by link flow based method covered only $26 \%$. Hence the ordering of links using information theory is found to be better.

\subsubsection{Validation of the Link Selection Procedure}

\section{Objective Function}

To validate the link selection procedure, the volumes on the links selected by the three methods were given as input to estimate the trip matrix for the network. The objective was to minimise the deviation between the estimated and observed link volumes, while satisfying the trip production and/or attraction constraints as given by the following equations suggested by Nagaraj and Samson (1992):

Minimise $F\left(V_{a}\right)=F\left(V_{a}, V_{a}^{\prime}\right)$

i.e. Minimise $\left[\left(\sum_{i=1}^{N} \sum_{j=1}^{N} T_{i j} P_{i j}\right)-V_{a}\right],(10)$

for $a=1,2, \ldots, M$

Subject to

$T_{i j} \geq 0$

$P_{i}-\delta_{i} \leq \sum_{j=1}^{N} T_{i j} \leq P_{i}+\delta_{i}$

for $i=1,2, \ldots, N$

$A_{j}-\delta_{j} \leq \sum_{i=1}^{N} T_{i j} \leq A_{j}+\delta_{j}$,

for $j=1,2, \ldots, N$ 


\section{Table 1}

Target OD Matrix for Hypothetical Network

\begin{tabular}{|c|c|c|c|c|c|c|c|c|}
\hline \multirow{2}{*}{$\begin{array}{c}\text { Origin } \\
\text { Zones }\end{array}$} & \multicolumn{9}{|c|}{ Destination Zones } \\
\cline { 2 - 9 } & $\mathbf{1}$ & $\mathbf{2}$ & $\mathbf{3}$ & $\mathbf{4}$ & $\mathbf{5}$ & $\mathbf{6}$ & $\mathbf{7}$ & $\mathbf{8}$ \\
\hline $\mathbf{1}$ & 0 & 821 & 1012 & 139 & 445 & 838 & 305 & 378 \\
\hline $\mathbf{2}$ & 231 & 0 & 917 & 203 & 932 & 126 & 190 & 860 \\
\hline $\mathbf{3}$ & 607 & 615 & 0 & 199 & 466 & 681 & 193 & 854 \\
\hline $\mathbf{4}$ & 486 & 792 & 894 & 0 & 419 & 380 & 682 & 594 \\
\hline $\mathbf{5}$ & 891 & 922 & 579 & 272 & 0 & 832 & 303 & 497 \\
\hline $\mathbf{6}$ & 762 & 738 & 353 & 199 & 525 & 0 & 541 & 899 \\
\hline $\mathbf{7}$ & 457 & 176 & 813 & 153 & 203 & 709 & 0 & 822 \\
\hline $\mathbf{8}$ & 185 & 406 & 99 & 747 & 672 & 429 & 698 & 0 \\
\hline
\end{tabular}

\section{Table 2}

Prioritised Links

\begin{tabular}{|l|l|}
\hline Weighting Method & Links Selected \\
\hline $\begin{array}{l}\text { Information Theory } \\
\text { Based Weighting }\end{array}$ & $33,20,14,15,6,41,8,1,9,17,34,7,22,24,23,5,13,4,19,21,10,2,12,18$ \\
\hline $\begin{array}{l}\text { Link Flow Based } \\
\text { Weighting }\end{array}$ & $6,48,26,19,31,44,10,36,24,34,13,45,33,7,8,4,40,39,41,32,23,5,18,2$ \\
\hline Equal Weighting & 1 to 24 \\
\hline
\end{tabular}

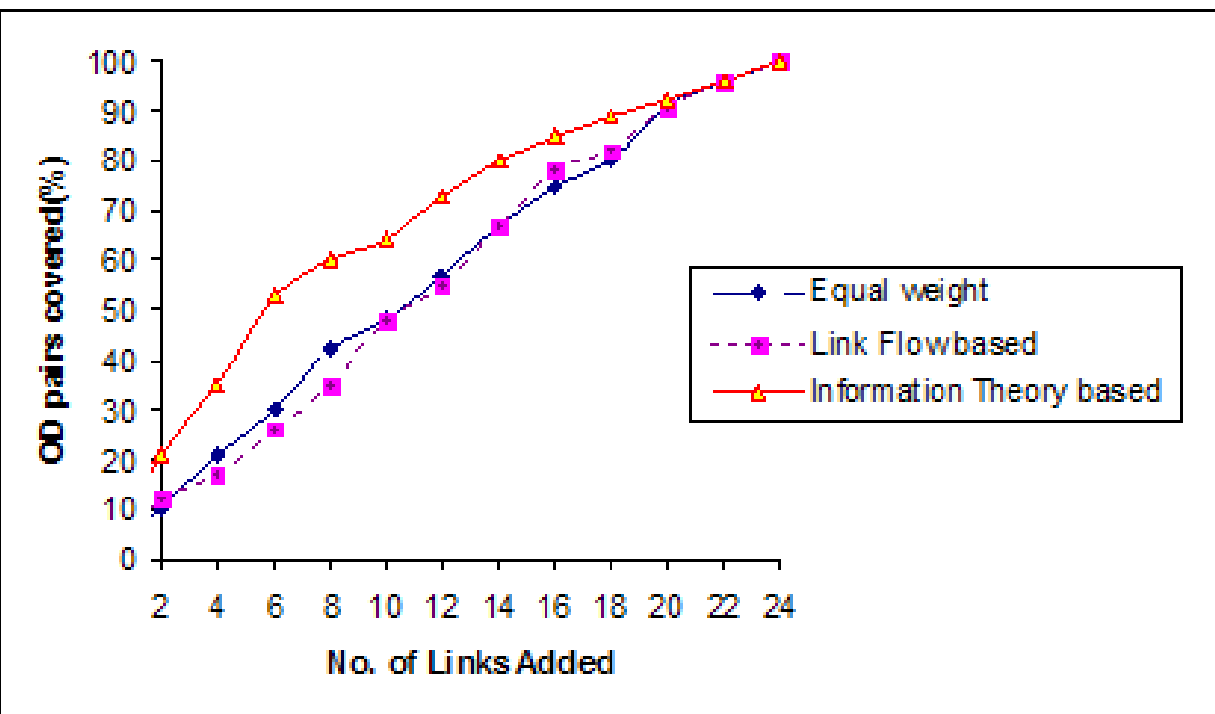

Fig. 2.

OD Pairs Covered with Addition of Links (\%) 
where,

$i=1,2, \ldots, N$

$j=1,2, \ldots, N$

$a=1,2, \ldots, M$

$V_{a}$ - Actual link volume

$\stackrel{a}{V_{a}^{\prime}}$ - Estimated link volume

$N$ - Number of zones

$M$ - Number of links with observed link volume

$P_{i}$ - Total trip productions of the zone $i$ with uncertainty $d_{i}$

$A_{j}$ - Total trip attractions to the zone $j$ with uncertainty $d_{j}$

$T_{i j}$ - Trip attraction to zone $j$ from zone $i$.

The constraints in Eq. (11) and Eq. (12) ensure that the sum of estimated trips originating from various zones and attracted to various zones satisfies the actual trip productions and attractions. The uncertainty was taken care of by incorporating a $5 \%$ deviation for total trip productions and attractions.

\subsubsection{Optimisation using Genetic Algorithm}

Genetic Algorithm (GA) has been widely accepted as an optimisation tool for solving multi-objective problems. Unlike other optimisation techniques, GA has the advantage that it searches for a global optimum and hence is adopted as an optimisation tool to solve many multiobjective demand estimation problem.

Genetic algorithm starts from a number of feasible solutions and undergoes the genetic operations to reach the optimal solution. In this study, Genetic algorithm was used as an optimisation tool for solving the objective function given in Eq. (10) subject to constraints in Eq. (11) and
Eq. (12). The algorithm for OD matrix estimation using Genetic algorithm was coded in Visual Fortran. The code by Deb (1998) for optimisation by genetic algorithm was modified. The upper and lower bounds for the trip values were specified to prevent the resulting trip matrix deviate away from the trend of the prior matrix.

For the hypothetical network used in this study, the trips between 56 OD pairs have to be estimated. Genetic algorithm starts with random values for these 56 unknowns and performs the genetic operations until the optimisation criteria (when the value of the objective function reaches to $2 \%$ of the total input link volume) are met or when the maximum specified iteration is completed.

The GA parameters adopted for the study are given below:

- $\quad$ Population size $=100$;

- $\quad$ Chromosome length = 640;

- $\quad$ Crossover probability $=0.6$;

- $\quad$ Mutation probability $=0.01$.

The stochastic remainder selection and single point cross over was adopted. The procedure was performed with the three sets of input links shown in Table 2. The output trip values were compared with the target matrix. The Root Mean Square Error (RMSE) and Mean Absolute Error (MAE) given by Eqs. (13-16) were used as a measure to assess the quality of estimated trip matrix and link volumes.

To compute the error of the estimated link volume, the links that were not used in the estimation process were selected. The results are shown in Table 3. 
Trip RMSE $=\sqrt{\frac{\sum_{w \in G}\left(T_{w}-\bar{T}_{w}\right)^{2}}{n}}$

$\operatorname{Trip}$ MAE $=\frac{\sum_{w \in G}\left|T_{w}-\bar{T}_{w}\right|}{n}$

where,

$T_{w}$ - Actual number of trips between OD pair $w$

$\bar{T}_{w}^{w}$ - Estimated number of trips between OD pair $w$

$n$ - Number of OD pairs with non-zero trips.

Volume RMSE $=\sqrt{\frac{\sum_{a=1}^{P}\left(V_{a}-\overline{V_{a}}\right)^{2}}{P}}$

Volume MAE $=\frac{\sum_{a=1}^{P}\left|V_{a}-\overline{V_{a}}\right|}{P}$ where,

$V$ - Actual volume on link $a$

$\bar{V}_{a}^{a}-$ Volume estimated by the model for link $a$

$P$ - Number of links selected for calculation of error of estimated OD matrix.

As seen from Table 3, the error in the output matrix and link volume is lower when the links selected by information theory based method was given as input. For e.g., the Trip RMSE when input links selected by information theory based method was used for estimation is 96.05 , by link flow method is 123.78 and for input links by equal weighting method, it is 112.02 . This infers that when links selected by information theory based method is given as input, a more reliable OD matrix is obtained. Hence it can be concluded that information theory based link selection procedure is better and hence these links are adopted for further work.

Earlier works have proved that if the input links satisfy the OD covering rule, a reliable trip matrix could be obtained. However, when there are budgetary constraints, it becomes necessary to select the links for traffic counts according to the available budget without satisfying the OD covering rule.

Table 3

Error in the OD Matrix and Link Volume for Input Links Selected by Different Methods

\begin{tabular}{|c|c|c|c|c|}
\hline \multirow{2}{*}{ Links Selected by: } & \multicolumn{2}{|c|}{$\begin{array}{c}\text { Error in Estimated OD Matrix } \\
\text { (persons) }\end{array}$} & \multicolumn{2}{c|}{$\begin{array}{c}\text { Error in the Estimated Link } \\
\text { Volume (persons) }\end{array}$} \\
\cline { 2 - 5 } & MAE & RMSE & MAE & RMSE \\
\hline $\begin{array}{c}\text { Information Theory } \\
\text { Based Method }\end{array}$ & 75.02 & 96.05 & 44.88 & 59.13 \\
\hline Link Flow Method & 87.23 & 123.78 & 55.88 & 80.14 \\
\hline Equal Weighting Method & 82.77 & 112.02 & 52.50 & 72.71 \\
\hline
\end{tabular}




\subsection{Validating the Prioritisation of Links}

To investigate if the ordering of links selected by information theory based method as given in Table 2 is valid, the volume of the prioritised links were added one by one as input and the Relative Root Mean Square Error (RRMSE) values of the output matrix for each case were found out by applying Eq. (17).

RRMSE of trips $(\%)=\frac{\sqrt{\frac{\sum_{w \in G}\left(T_{w}-\bar{T}_{w}\right)^{2}}{n}}}{\frac{\sum \bar{T}_{w}}{n}} \times 100$

where,

$T_{w}$ - Actual number of trips between OD pair $w$

$\bar{T}_{w}^{w}-$ Estimated number of trips between OD pair $w$

$n$ - Number of OD pairs with non-zero trips.

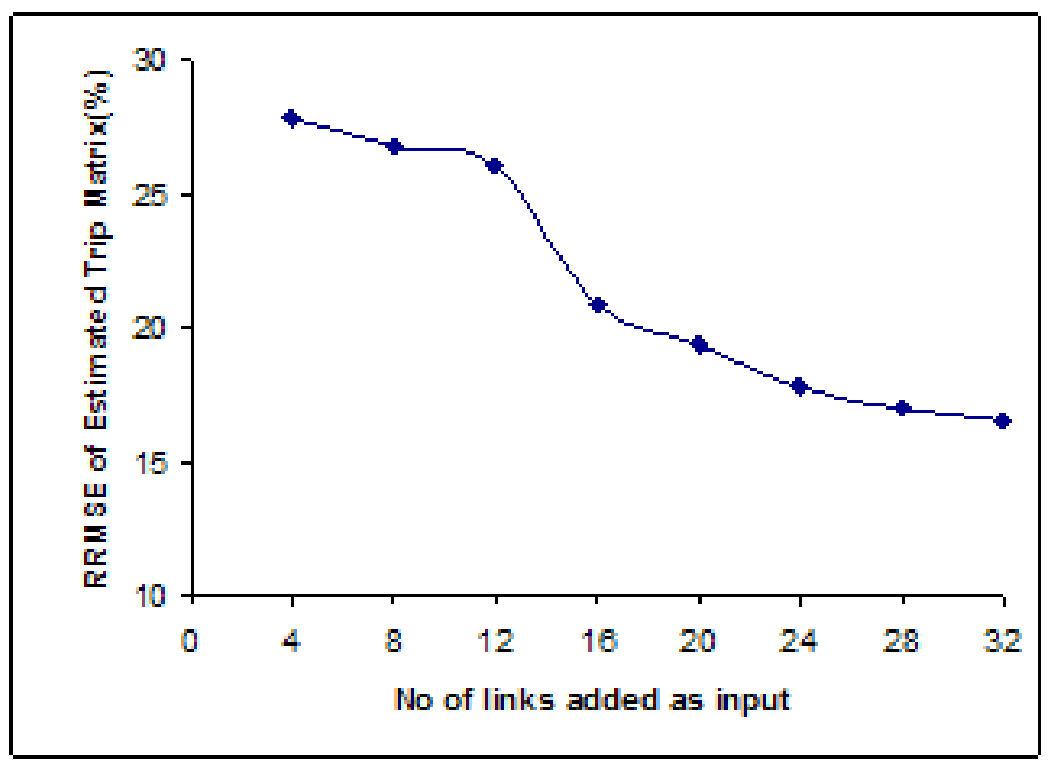

Fig. 3.

Variations in Error of Estimated Trip Matrix with Addition of Links

ijtte 122 
RRMSE of link volume $(\%)=\frac{\sqrt{\frac{\sum_{i=1}^{P}\left(V_{a}-\overline{V_{a}}\right)^{2}}{P}}}{\frac{\sum \overline{V_{a}}}{P}} \times 100$

where,

$V$ - Actual volume on link $a$

$\bar{V}_{a}^{a}$ - Volume estimated by the model for link $a$

$P$ - Number of links selected for calculation of error of estimated OD matrix.

The links were added in the order of their information content starting with the most important link. The error in the estimated volume was also found out. To calculate the error of the estimated link volume, the links that were not used in the estimation process were selected. The errors are plotted in Fig. 3 and Fig. 4. It can be seen from the figures that the error of the estimated OD matrix reduces as more links are added. When the input links were increased to more than half of that required for complete OD coverage, there is sudden drop in error of trip matrix and link volume.

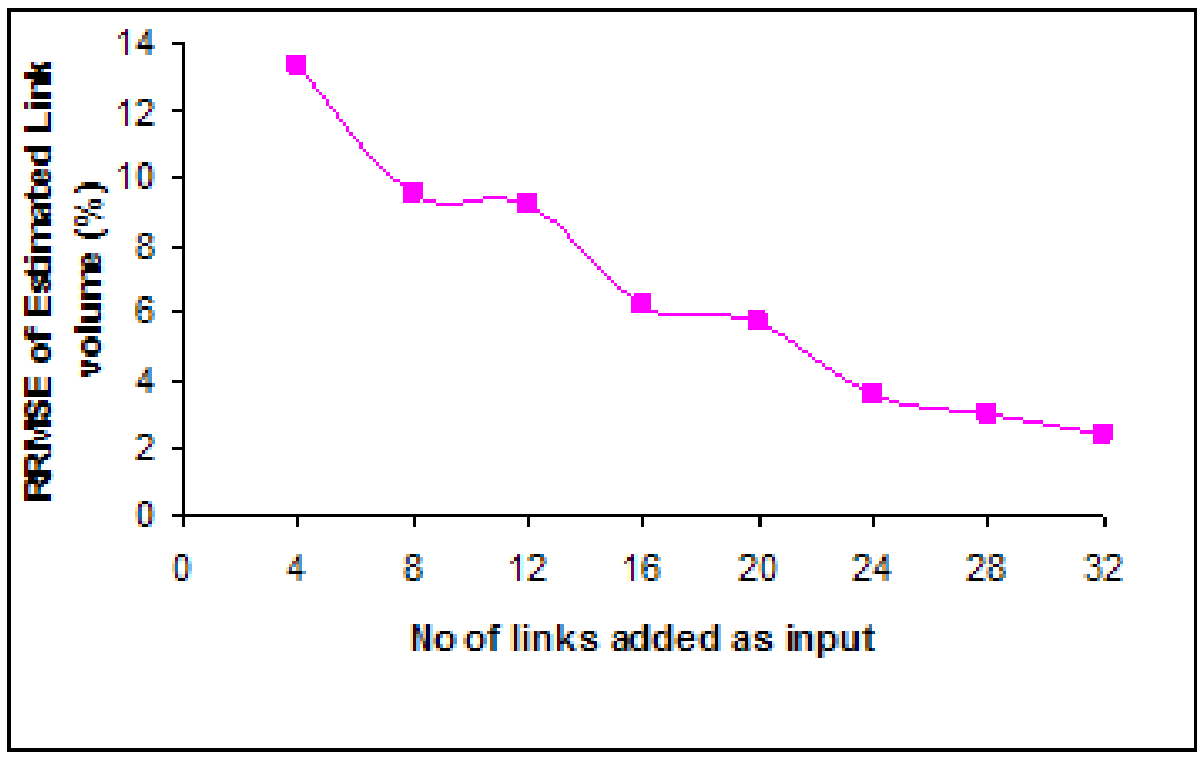

Fig. 4.

Variation in Error of Estimated Volume with Addition of Links 
When the links cover all OD pairs, the trip values predicted by the model are very near the true values. When the links added is more than that required for complete OD coverage, the reduction in error is less. The trip matrix estimated when the volumes of all the links selected by information theory method (given in Table 2) are added as input, is compared with the actual trips and the scatter diagram plotted is shown in Fig. 5.

It can be observed that most of the points are very close to $45^{\circ}$ line, which explains a good correlation between the actual and estimated values. In this case, the error in the output matrix is only $17.85 \%$ and the link volume is estimated with an error of only $3.55 \%$.

\section{Conclusions}

Indirect estimation of $\mathrm{OD}$ matrix necessitates the knowledge of link volume counts in the network.
For this, it is mandatory to select the links for traffic counts. If the links in a network are prioritised, the input links for trip estimation can be sorted out from the prioritised link set. This study utilized the information theory to rank the links in a network on the basis of its information content. The results of this study prove that the ordering of links based on information theory gives good results. The methodology will help to prioritise the optimum links in a network. The links can be selected from the prioritised set according to the budgetary constraints for OD matrix estimation. The study underlines the fact that if a prior matrix of the study area is available, information theory can be applied to find the information content of OD pairs in a transportation network and the links can be prioritised by assigning weights based on information theory approach. The prioritisation of links based on the method suggested here can be utilised for indirect estimation of OD matrix from link volume counts.

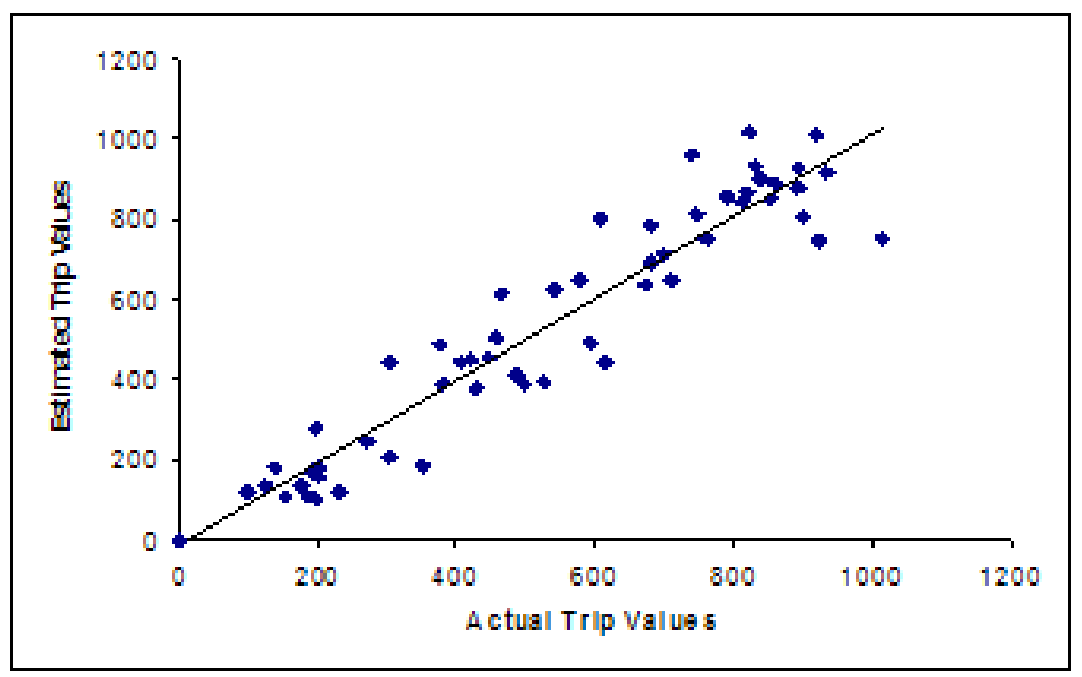

Fig. 5.

Correlation between the Estimated and Actual Trip Matrix 


\section{Acknowledgements}

The authors express their sincere thanks to The Kerala State Council for Science Technology and Environment (KSCSTE) for funding this research.

\section{References}

Baek, S.; Kim, H.; Lim, Y. 2004. Multiple - vehicle origindestination matrix estimation from traffic counts using genetic algorithm, Journal of Transportation Engineering. DOI: http://dx.doi.org/10.1061/(ASCE)0733947X(2004)130:3(339), 130(3): 339-347.

Bera, S.; Rao, K.V.K. 2011. Estimation of origin-destination matrix from traffic counts: the state of the art, European Transport \Trasporti Europei, 49(2011): 3-23.

Boschetti, M.A.; Maniezzo, V.; Roffilli, M.; Röhler, A.J.B. 2011. Matheuristics for Traffic Counter location. In Proceedings of the VII ALIO-EURO - Workshop on Applied Combinatorial Optimization, Porto, Portugal. 77-80.

Cipriani, E.; Fusco, G.; Gori, S.; Petrelli, M. 2006. Heuristic methods for the optimal location of road traffic monitoring stations. In Proceedings of the IEEEITSC, Toronto, Canada. 17-20.

Deb, K. 1998. Optimisation for engineering design: algorithms and examples, Prentice Hall of India. 290-319.

Doblas, J.; Benitez, G. 2005. An approach to estimating and updating origin-destination matrices based upon traffic counts preserving the prior structure of a survey matrix, Transportation Research Part B: Methodological. DOI: http://dx.doi.org/10.1016/j.trb.2004.06.006, 39(7): 565-591.

Ehlert, A.; Bell, M.G.H.; Grosso, S. 2006. The optimisation of traffic count locations in road networks, Transportation Research Part B: Methodological. DOI: http://dx.doi. org/10.1016/j.trb.2005.06.001, 40(6): 460-479.

Gan, L.; Yang, H.; Wong, C.S. 2005. Traffic counting location and error bound in origin-destination matrix estimation problems, Journal of Transportation Engineering. DOI: http://dx.doi.org/10.1061/(ASCE)0733947X(2005)131:7(524), 131(7): 524-534.

Goldberg, D.E. 2004. Genetic algorithms in search, optimization and machine learning, Addison-Wesley, Reading, Mass, USA. 161-185.

Gothe, M.B.; Jornsten, K.O.; Lundgren, J.T. 1989. Estimation of origin destination matrices from traffic counts using multi objective programming formulation, Transportation Research Part B: Methodological. DOI: http:// dx.doi.org/10.1016/0191-2615(89)90028-3, 23(4): 257269.

Hazelton, M.L. 2000. Estimation of origin destination matrices from link flows on uncongested networks, Transportation Research Part B: Methodological. DOI: http:// dx.doi.org/10.1016/S0191-2615(99)00037-5, 34(7): 549-566.

Hazelton, M.L. 2003. Some comments on origindestination matrix estimation, Transportation Research Part A: Policy and Practice. DOI: http://dx.doi.org/10.1016/ S0965-8564(03)00044-2, 37(10): 811-822.

Kim, H.J.; Chung, I.H.; Chung, S.Y. 2003. Selection of the optimal traffic counting locations for estimating origin destination trip matrix, Journal of the Eastern Asia Society for Transportation Studies, 5(2003): 1353-1365.

Lorenzo, M.; Susan, G.T.; Haibo, C. 2010. A neural network approach to motorway OD matrix estimation from loop counts, Journal of Transportation systems Engineering and Information Technology. DOI: http://dx.doi. org/10.1016/S1570-6672(09)60026-X, 10(1): 88-98.

Nagaraj, B.N.; Samson, M. 1992. Estimation of origin destination matrices from link volume counts. In Proceedings of the National Seminar on Urban Transportation, CRRI, II.11-22.

Shannon, C.E. 1948. A mathematical theory of communication, Bell System Technical Journal, 27(1948): 379-423; 623-656. 
Sherali, H.D.; Narayanan, A.; Sivanandan, R. 2003. Estimation of origin-destination trip tables based on partial set of traffic link volumes, Transportation Research Part B: Methodological. DOI: http://dx.doi.org/10.1016/ S0191-2615(02)00073-5 37(9): 815-836.

Vanzuylen, H.J.; Willumsen, L.G. 1980. The most likely trip matrix estimated from traffic counts, Transportation Research Part B: Methodological. DOI: http://dx.doi. org/10.1016/0191-2615(80)90008-9, 14(3): 281-293.

Wang, H.; Li, K.P.; Sun, J.; Liu, Y. 2008. Framework on hierarchical optimization of traffic count location for city traffic system. In Proceedings of the Workshop on Power Electronics and Intelligent Transportation System. 419-422.

Wong, C.; Tong, C.O.; Wong, K.I.; Lam, W.H.K.; Lo, H.K.; Yang, H.; Lo, H.P. 2005. Estimation of multi class origin destination matrices from traffic counts, Journal of Urban Planning and Development. DOI: http://dx.doi.org/10.1061/ (ASCE)0733-9488(2005)131:1(19), 131(1): 19-29.

Yang, H.; Iida, T.; Sasaki, T. 1991. An analysis of the reliability of an origin destination trip matrix estimated from traffic counts, Transportation Research Part B: Methodological. DOI: http://dx.doi.org/10.1016/01912615(91)90028-H, 25(5): 351-363.

Yang, H.; Zhou, J. 1998. Optimal traffic counting locations for origin-destination matrix estimation, Transportation Research Part B: Methodological. DOI: http://dx.doi. org/10.1016/S0191-2615(97)00016-7, 32(2): 109-126.

Yang, C.; Chootinan, P.; Chen, A. 2003. Traffic counting location planning using genetic algorithms, Journal of the Eastern Asia Society for Transportation Studies, 5(2003): 898-913.

Yang, H.; Yang, C.; Gan, L. 2006. Models and algorithms for the screen line - based traffic - counting location problems, Computers and Operations Research. DOI: http:// dx.doi.org/10.1016/j.cor.2004.08.011, 33(3): 836-858.

\section{ODREĐIVANJE PRIORITETNIH LOKACIJA BROJANJA SAOBRAĆAJA ZA PROCENU MATRICE KRETANJA PRIMENOM TEORIJE INFORMACIJA}

\section{Manju V. Saraswathy, Kuncheria P. Isaac}

Sažetak: Najvažniji korak u proceni izvornociljne (IC) matrice na osnovu protoka na deonicama predstavlja optimalan izbor samih deonica. U ovom radu je predložena metodologija određivanja prioritetnih deonica primenom teorije informacija. Deonicama su dodeljeni težinski faktori u zavisnosti od informacija i optimalne deonice koje ispunjavaju pravilo pokrivenosti su određene na osnovu binarnog celobrojnog programiranja. Prioritet deonica je određen na osnovu dodeljenih težinskih faktora. Metodologija je primenjena na hipotetičkoj mreži. Validacija metodologije je sprovedena na osnovu razlike u protocima utvrđenih brojanjem saobraćaja i onih dobijenih raspodelom saobraćaja iz IC matrice. Primećeno je da procena IC matrice kretanja upotrebom podataka sa deonica selektovanih na osnovu teorije informacija obezbeđuje najmanju grešku. Takođe je utvrđeno da je razmatrani metod za utvrđivanje prioriteta pogodan u slučaju postojanja budžetskih ograničenja za izbor deonica.

Ključne reči: IC matrica kretanja, teorija informacija, lokacije brojanja saobraćaja, protok na deonici. 